\title{
Ligational Behavior of Synthesized New Hydrazones Towards Oxovanadium (IV) Complexes and Their Antituberculosis Aspects
}

\author{
Dr. Alok Chandrayan \\ Government Motilal Vigan Mahavidhayalaya \\ Bhopal, India \\ drralokchandrayan@gmail.com
}

\author{
Dr. Alka Pradhan \\ Government Motilal Vigan Mahavidhayalaya \\ Bhopal, India
}

\begin{abstract}
The synthesis of some oxovanadium (IV) complexes with bidentate ligands (new synthesized biologically active hydrazones) derived from 2-methyl-4(N-cyanoethyl)-N-benzenesulphonyl-benzylidene-3-oxo[N-(substituted-1-phenyl)propanamido] hydrazone were analyzed. The complexes prepared were of the type [VO.L $L_{2}$ (where $L=$ different new synthesized hydrazones).The characterization of these newly synthesized hydrazones and their metal complexes were done by IR, ${ }^{1}$ H-NMR spectral studies and elemental analysis. The infrared data of these complexes revealed the bidentate nature of the ligands and coordination to imino nitrogen of the amido group and azomethinic-nitrogen atoms. The new products were synthesized and evaluated for anti-tuberculosis activity against Mycobacterium tuberculosis $\mathbf{H}_{37} \mathrm{Rv}_{\mathrm{v}}$ in L.J.medium. The biological screening data indicates that the metal chelates are more potent than the parent ligands.
\end{abstract}

\section{INTRODUCTION}

Hydrazone compounds obtained by the reaction of aromatic and heterocyclic hydrazides with mono- and di-aldehydes or ketones have revealed very versatile behavior in metal coordination ${ }^{1}$. Many researchers have synthesized a number of new hydrazones because of their ease of synthesis ${ }^{2}$.

Hydrazones play an important role in inorganic chemistry as they easily form stable complexes with most transition metal ions in the periodic table the development of the field of bioinorganic chemistry has increased the interest in hydrazone complexes, as they have been recognized that many of these complexes may serve as models for biologically important species. The remarkable biological activity of acid hydrazides $\mathrm{R}-\mathrm{CO}-\mathrm{NH}-\mathrm{NH}_{2}$, their corresponding hydrazones, R-CO-NH$\mathrm{N}=\mathrm{CH}-\mathrm{R}$ ' and the dependence of their mode of chelation with transition metal ions present in the living system, have been of significant interest in the past ${ }^{3-6}$. The coordination compounds of aroylhydrazones have been reported to act as enzyme inhibitors $^{7}$ and are useful due to their pharmacological application ${ }^{8-10}$. Isonicotinic acid hydrazide is a drug of proven therapeutic importance and used against a wide spectrum of bacterial ailments, as tuberculosis ${ }^{11}$.

Hydrazones have been studied as a group of the most useful spectrophotometric reagents ${ }^{2}, 12,13$. Combining appropriate starting materials (carbonyl compounds and hydrazine), the sensitivity as an analytical reagent and / or solubility of the hydrazones could be improved and the donating environment could be changed. The shortcoming of hydrazones was their lack of selectivity ${ }^{2}$ for metal ions. Much effort has been devoted to developing masking agents for use with hydrazones ${ }^{14,15}$.

High-performance liquid chromatography (HPLC) of metal chelates ${ }^{16}$ is a promising alternative approach for overcoming the lack of selectivity of the chelating reagents ${ }^{2}$. hydrazone ligands and their complexes have been studied for their antifungal and antibacterial activity, as iron chelators in the treatment of anemias and as antiviral drugs ${ }^{1}$.

The coordination chemistry of oxovanadium (IV) with multidentate ligands is important due to its growing application in catalysis $^{17}$ and therapeutics ${ }^{18}$. Vanadium in traces has multiple biological roles, therapeutic value in small doses and toxic in excess. Vanadium containing compounds have their utility as insulin mimetic ${ }^{19}$ and antiamoebic agent ${ }^{20}$.

It is also suggested that vanadium could be considered as a representative of a new class of non-platinum metal antitumour agents 21 . In the present investigation we describe the synthesis 
and characterization of some new hydrazones and their oxovanadium (IV) complexes.

Where $\mathbf{R}=-\mathbf{C l}$ and $-\mathbf{N O}_{2}$

\section{II.STRUCTURE OF NEW SYNTHESIZED HYDRAZONE Ball Stick modal of new synthesized Hydrazone}

\section{RESULTS AND DISCUSSION}

All compounds gave satisfactory results for elemental analysis, IR and ${ }^{1} \mathrm{H}-\mathrm{NMR}$ spectra. The physical and analytical data of synthesized new hydrazones and their metal complexes are presented in table-1.

Table 1: Analytical Data of Synthesized hydrazones and their Metal Complexes

\begin{tabular}{|c|c|c|c|c|c|c|c|}
\hline \multirow{2}{*}{ Compounds } & \multirow{2}{*}{$\begin{array}{l}\text { Mol. Formula (Mol. } \\
\text { Wt.) }\end{array}$} & \multirow{2}{*}{ M.P $\left({ }^{0} \mathrm{C}\right)$} & \multirow{2}{*}{$\begin{array}{c}\text { Colour } \\
(\text { yield \%) }\end{array}$} & \multicolumn{4}{|c|}{$\begin{array}{c}\text { Elemental Analysis (\%) } \\
\text { Calculated/ Found) }\end{array}$} \\
\hline & & & & $\mathbf{C}$ & $\mathbf{H}$ & $\mathbf{N}$ & $\mathbf{M}$ \\
\hline МСРН & $\begin{array}{c}\mathrm{C}_{26} \mathrm{H}_{24} \mathrm{~N}_{5} \mathrm{O}_{4} \mathrm{SCl} \\
(538.03)\end{array}$ & 207 & $\begin{array}{l}\text { Brown } \\
\text { (71) }\end{array}$ & $\begin{array}{l}58.04 \\
(58.00)\end{array}$ & $\begin{array}{r}04.50 \\
(04.48)\end{array}$ & $\begin{array}{r}13.02 \\
(13.00)\end{array}$ & $\begin{array}{l}- \\
-\end{array}$ \\
\hline MNPH & $\begin{array}{c}\mathrm{C}_{26} \mathrm{H}_{24} \mathrm{~N}_{6} \mathrm{O}_{6} \mathrm{~S} \\
(548.58)\end{array}$ & 212 & $\begin{array}{l}\text { Yellow } \\
\text { (75) }\end{array}$ & $\begin{array}{c}56.93 \\
(56.87)\end{array}$ & $\begin{array}{c}04.41 \\
(04.35)\end{array}$ & $\begin{array}{c}15.32 \\
(15.28)\end{array}$ & $\begin{array}{l}- \\
-\end{array}$ \\
\hline $\begin{array}{l}\text { [VO(IV)- } \\
\left.(\mathrm{MCPH})_{2}\right]\end{array}$ & $\begin{array}{c}\mathrm{VO}(\mathrm{IV})- \\
\left(\mathrm{C}_{52} \mathrm{H}_{48} \mathrm{~N}_{10} \mathrm{O}_{8} \mathrm{~S}_{2} \mathrm{Cl}_{2}\right) \\
(1143.00)\end{array}$ & 223 & $\begin{array}{l}\text { Light Blue } \\
\qquad(68)\end{array}$ & $\begin{array}{l}54.59 \\
(54.50)\end{array}$ & $\begin{array}{l}04.19 \\
(04.11)\end{array}$ & $\begin{array}{l}12.24 \\
(12.19)\end{array}$ & $\begin{array}{r}04.45 \\
(04.38)\end{array}$ \\
\hline $\begin{array}{l}{\left[\mathrm{VO}(\mathrm{IV})_{-}\right.} \\
\left.(\mathrm{MNPH})_{2}\right]\end{array}$ & $\begin{array}{c}\mathrm{VO}(\mathrm{IV})- \\
\left(\mathrm{C}_{52} \mathrm{H}_{48} \mathrm{~N}_{12} \mathrm{O}_{12} \mathrm{~S}_{2}\right) \\
(1164.10)\end{array}$ & 230 & $\begin{array}{l}\text { Dark Blue } \\
\qquad(70)\end{array}$ & $\begin{array}{l}53.60 \\
(53.55)\end{array}$ & $\begin{array}{l}04.12 \\
(04.08)\end{array}$ & $\begin{array}{r}14.43 \\
(14.37)\end{array}$ & $\begin{array}{r}04.37 \\
(04.30)\end{array}$ \\
\hline
\end{tabular}

Infrared Spectra: Comparative study of the IR of hydrazones<smiles>[R]c1ccc(NC(=O)CC(=O)NN=Cc2ccc(N(CCC#N)S(=O)(=O)c3ccccc3)cc2C)cc1</smiles>

and metal complexes are helpful in evaluating the results.

Spectral interpretation of new hydrazones show characteristic bands i.e. $v(\mathrm{~N}-\mathrm{H})$ stretching: $3320-3060 \mathrm{~cm}^{-1}, v(\mathrm{C}=\mathrm{O})$ stretching: $1750-1650 \mathrm{~cm}^{-1}$ and azomethine nitrogen: 1640 $1610 \mathrm{~cm}^{-1}$.

A strong band around $1630 \mathrm{~cm}^{-1}$ indicates the formation of new hydrazone because this band appears due to condensation of hydrazide with aldehyde, when these hydrazones chelate with metals, the normal frequency of $v(\mathrm{C}=\mathrm{O})$ stretching band is shifted towards lower frequency region.

The lowering by $10-30 \mathrm{~cm}^{-1}$ in $v(\mathrm{C}=\mathrm{N})$ azomethine nitrogen babd frequency around 1700-1600 $\mathrm{cm}^{-1}$ suggests the coordination of hydrazone ligand to the metal ion through imino nitrogen of the amido group and azomethine nitrogen. Some new bands present in far infrared region $\left(690-650 \mathrm{~cm}^{-1}\right.$ \& 980-900 $\left.\mathrm{cm}^{-1}\right)$ shows the formation of some new [ $v(\mathrm{~V}-\mathrm{N})$ and $v(\mathrm{~V}-\mathrm{O})]$ bands in the spectra of metal complexes .

In all the complexes of $\mathrm{VO}^{2+}$, the $\mathrm{V}=\mathrm{O}$ (oxovanadium) stretching frequency occurs in the range $975-960 \mathrm{~cm}^{-1}$. These values are in the range observed for monomeric $\mathrm{VO}^{2+}$ complexes $^{22}$. The $\mathrm{d} \pi-\mathrm{p} \pi$ orbital overlap involved in a multiple bond. This strong multiple bonding with the oxygen appears to be responsible for the trans influence of the oxo ligand, which disfavors attachment of a ligand trans to $\mathrm{O}^{23}$.

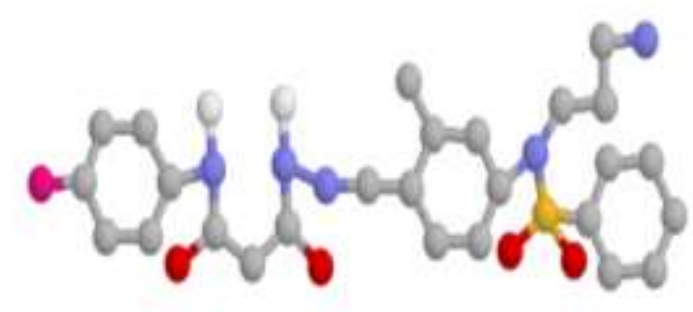


Table 2: Infrared absorption frequencies $\left(\mathrm{cm}^{-1}\right)$ of Hydrazones and their Metal Complexes

\begin{tabular}{|c|c|c|c|c|}
\hline Compounds & $v(\mathrm{NH})$ & $v(\mathrm{C}=\mathrm{N})$ & $v(\mathrm{~V}=\mathrm{O})$ & $\begin{array}{c}v(\mathrm{~V}- \\
\mathrm{N})\end{array}$ \\
\hline MCPH & $3230 \mathrm{~m}$ & $1620 \mathrm{~s}$ & - & - \\
\hline MNPH & $3225 \mathrm{~m}$ & $1627 \mathrm{~s}$ & - & - \\
\hline $\begin{array}{c}{\left[\mathrm{VO}(\mathrm{IV})_{-}\right.} \\
\left.(\mathrm{MCPH})_{2}\right]\end{array}$ & $3210 \mathrm{~m}$ & $1600 \mathrm{~s}$ & $975 \mathrm{~m}$ & $665 \mathrm{~m}$ \\
\hline $\begin{array}{c}{\left[\mathrm{VO}(\mathrm{IV})_{-}\right.} \\
\left.(\mathrm{MNPH})_{2}\right]\end{array}$ & $3210 \mathrm{~m}$ & $1605 \mathrm{~s}$ & $978 \mathrm{~m}$ & $673 \mathrm{~m}$ \\
\hline
\end{tabular}

${ }^{1}$ H-NMR Spectra: The ${ }^{1} \mathrm{H}-\mathrm{NMR}$ spectra of new synthesized hydrazones MCPH and MNPH were recorded (Table-3). The spectra in comparison to the corresponding hydrazide, show the disappearance of $\mathrm{NH}_{2}$ group signal, while that of the $\mathrm{NH}$ protons are shows low field to the range $\delta 8.90-11.80 \mathrm{ppm}$ for the imino proton present in ligands ${ }^{24}$ ( hydrazones) .

The protin of azomethine group $(\mathrm{CH}=\mathrm{N})$ sharp peak is observed at $\delta 8.50-8.80 \mathrm{ppm}$. Further two signals observed at $\delta 3.60-3.90 \mathrm{ppm}$ are assigned to methylene protons $\mathrm{s}^{25}$. The multiplet due to aromatic protons appears in the $\delta 7.03-8.30$ ppm region. The appearance of two doublets in the region $\delta$ $11.11-12.96 \mathrm{ppm}$ coupled with signals at $\delta 3.60-3.90 \mathrm{ppm}$ suggests enolization of hydrazones involving active methylene group with keto-enol equilibrium in the solution. Thus, the signal at $\delta 3.60 \mathrm{ppm}$ may be attributed to methylene $\left(-\mathrm{CH}_{2}-\right)$ and that at $\delta 3.90 \mathrm{ppm}$ to methane proton $(=\mathrm{CH}-)$.

The bonding of ligand to metal is further supported by ${ }^{1} \mathrm{H}-$ NMR spectral studies and NMR spectra (Table 3) recorded for [VO-(MCPH $)_{2}$ ] and [VO-(MNPH $)_{2}$ ]. The signals in the $\delta 11-$ $13 \mathrm{ppm}$ region are medium, broad and shifted upfeild by about $0.38-0.45 \mathrm{ppm}$ in the complex as compared to that in the free hydrazone in which they are relatively intense indicating that they arise due to secondary (imino) $-\mathrm{NH}$ protons ${ }^{25}$. This suggests coordination of the imino nitrogen (amido group) atoms to the metal center. In the spectrum of oxovanidium complex of hydrazones (MCPH and MNPH) position of $\delta$ $\mathrm{CH}=\mathrm{N}$ - signal shifts down field by $0.49-0.65$ ppm suggesting coordination of azomethine nitrogen atoms to the metal center. ${ }^{25}$.

Table 3: ${ }^{1} \mathrm{H}-\mathrm{NMR}$ Spectral data of hydrazones and their metal complexes

\begin{tabular}{|c|c|c|c|c|}
\hline Compounds & -N-H & -CH=N- & - $\mathbf{H}_{2}$ - & Ar-H \\
\hline MCPH & $11.2(1 \mathrm{H}, \mathrm{m})$ & $8.5(1 \mathrm{H}, \mathrm{s})$ & $3.6(2 \mathrm{H}, \mathrm{m})$ & $7.10-8.00(12 \mathrm{H}, \mathrm{m})$ \\
\hline $\mathrm{MNPH}$ & $11.5(1 \mathrm{H}, \mathrm{m})$ & $8.7(1 \mathrm{H}, \mathrm{s})$ & $3.8(2 \mathrm{H}, \mathrm{m})$ & $7.15-8.10(12 \mathrm{H}, \mathrm{m})$ \\
\hline$\left[\mathrm{VO}(\mathrm{IV})-(\mathrm{MCPH})_{2}\right]$ & $11.6(1 \mathrm{H}, \mathrm{m}, \mathrm{bro})$. & $7.9(1 \mathrm{H}, \mathrm{s})$ & $3.5(2 \mathrm{H}, \mathrm{m})$ & $7.05-7.90(12 \mathrm{H}, \mathrm{m})$ \\
\hline$\left[\mathrm{VO}(\mathrm{IV})-(\mathrm{MNPH})_{2}\right]$ & $11.9(1 \mathrm{H}, \mathrm{m}, \mathrm{bro})$. & $8.1(1 \mathrm{H}, \mathrm{s})$ & $3.7(2 \mathrm{H}, \mathrm{m})$ & $7.09-8.00(12 \mathrm{H}, \mathrm{m})$ \\
\hline
\end{tabular}

\section{ANTITUBERCLOSIS ACTION}

A close study of table 4 revels that all the four synthesized new compounds screened for their antitubercular effect against $\mathrm{M}$. tuberculosis, the compound Iia was found to show remarkable effect (MIC $100 \mu \mathrm{g} / \mathrm{ml}$ ).

Moreover, the compounds Ia and Iib exhibited a moderate activity (MIC $250 \mu \mathrm{g} / \mathrm{ml}$ ). However, the compound having codes as Ib showed mild activity (MIC $500 \mu \mathrm{g} / \mathrm{ml}$ ).

In the present study small number of isolates $(n=04)$ were tested for their antitubercular susceptibility.

It would be appropriate to study the same impact of the synthesized new compounds on a still larger number of isolates obtained from variety of clinical samples, so as to study the spectrum of effectivity of these compounds.
With the increasing number of multi-drug resistance of $\mathrm{M}$. tuberculosis, it is desirable to start anti-tubercular therapy only after sensitivity assay to determine the most suitable drug against particular isolate infecting to patient. Moreover, with increasing prevalence of tuberculosis, there is a need of regular development of newer and newer anti tubercular drugs for the effective management of tuberculosis in patients, thus here lies the importance of the investigated compounds of organic origin.

\section{V.CONCLUSION}

In this paper coordination chemistry of a newly synthesized hydrazone ligands, obtained from the reaction of 3-oxo-[ $\mathrm{N}$ (substituted -1-phenyl) propanamido ] hydrazide and 2methyl-4-( N-cyanoethyl )-N-benzenesulphonyl benzaldehyde 
, is described. Oxovanadium (IV) complexes have been synthesized using the above newly hydrazone ligands and characterized on the basis of analytical, IR ${ }^{1} \mathrm{H}-\mathrm{NMR}$ spectral data. The observation of newly hydrazone ligand to the metal ion through imino nitrogen of the amido group and azomethine nitrogen and acts as a bidentate ligand. In all the synthesized metal complexes of vanadium metal attached oxygen atom to monomeric $\left(\mathrm{VO}^{+2}\right)$ form because of the $\mathrm{d} \pi$-p $\pi$ orbital overlap involved in a multiple bond. This strong multiple bonding with the oxygen appears to be responsible for the trans-influence of the oxo-ligand, which disfavors attachment of a ligand trans to oxygen.

The biological screening data of indicare that the metal chelates are more potent than the parent ligands.

\section{EXPERIMENTAL}

Materials and Instrumentation: All reagents used were purchased from Merck and used as received. Melting points were taken in open capillary and are uncorrected. Elemental analyses, ${ }^{1} \mathrm{H}$-NMR spectra were obtained on a Bruker FT-400 spectometer using $\mathrm{CDCl}_{3}$ as solvent and TMS as an internal standard. IR spectra were recorded on $\mathrm{KBr}$ disks, using a Jasco-410 FTIR spectrometer. All the hydrazides were prepared by the reaction of hydrazine hydrate with different esters.

3-oxo-[N-(4-chloro-1-phenyl) propanamido] hydrazide, 3oxo-[N-(4-nitro-1-phenyl) propanamido] hydrazide ${ }^{26}$ and 2methyl-4-(N-cyanoethyl)

-N-benzenesulphonyl benzaldehyde ${ }^{27}$ were prepared by reported methods.

(A) Preparation of Hydrazones : Synthesis of 2-methyl-4(N-cyanoethyl) -N-benzenesulphonyl benzylidene-3-oxo-[ $\mathrm{N}$ (4-chloro-1-phenyl) propanamido] hydrazone (MCPH) (Ia) : 3oxo-[ N-(4-chloro-1-phenyl) propanamido] hydrazide $(0.227 \mathrm{gm}, 0.001 \mathrm{~mol})$ and 2-methyl-4- (N-cyanoethyl)-Nbenzenesulphonyl benzaldehyde $(0.328 \mathrm{gm}, 0.001 \mathrm{~mol})$ were dissolved in ethanol and added a drop of concentrated $\mathrm{H}_{2} \mathrm{SO}_{4}$. Mixture was stirred for $5 \mathrm{~min}$. The resulting solid was recrystallised from ethanol as brown crystals (71\%).

(II) Synthesis of 2-methyl-4-(N-cyanoethyl) -Nbenzenesulphonyl benzylidene-3-oxo-[N-(4-nitro-1-phenyl) propanamido] hydrazone (MNPH) (Ib) [yellow crystals (75\%)] was prepared similarly.

\section{(B) Preparation of the metal complexes of $\mathrm{MCPH}$ and MNPH :}

To a hot solution of the respective metal salt [0.173gm vanadyl chloride $\left.\left(\mathrm{VOCl}_{2} \cdot 2 \mathrm{H}_{2} \mathrm{O}\right)\right]$ in methanol was added a sufficient amount of the MCPH $(0.538 \mathrm{gm})$ or MNPH $(0.548 \mathrm{gm})$. The solution was mixed with a required stoichiometric amount of the respective ligand in hot methanol. The resulting mixture was refluxed for four hours and then concentrated to half of its volume. On cooling, a colored crystalline product was obtained
, which was filtered, washed with organic solvents and dried in a vaccum oven .

\section{(C) Biological experiments:}

A series of newly synthesized compounds have been tested for their anti-tubercular effect on M. tuberculosis ${ }^{28-30}$. Four different strains of M.tuberculosis isolated from various clinical specimens belonging to pulmonary and extrapulmonary patients (sputum, pleural fluid, pus and lymph node aspirate). Standard strain of $M$. tuberculosis i.e. $\left(H_{37} R_{V}\right)$ was used as control strain. All test compounds of varying concentration ranging from $1600 \mu \mathrm{g} / \mathrm{ml}-50 \mu \mathrm{g} / \mathrm{ml}$.

The L .J. Media containing different test compounds were brought at room temperature . $100 \mu$ of seed culture was applied to each slant of L. J. Medium containing different test compounds. A fresh disposable loop was used for each slant. The cap was closed tightly and slants were incubated at $37 \pm 0.5^{0} \mathrm{C}$.

All the cultures, incubated at $37^{\circ} \mathrm{C}$ were observed initially twice in a week for a period of three weeks and later weekly for a total period of eight weeks for the growth of AFB. Results were noted according to the minimum effective concentration inhibiting the growth of AFB on the medium.

Table 4: MIC values of newly synthesized compounds

\begin{tabular}{|c|c|c|}
\hline Code No. & Name of Compounds & MIC Values $(\boldsymbol{\mu g} / \mathbf{m l})$ \\
\hline Ia & MCPH & 250 \\
\hline Ib & MNPH & 500 \\
\hline IIa & {$\left[\mathrm{VO}(\mathrm{IV})-(\mathrm{MCPH})_{2}\right]$} & 100 \\
\hline IIb & {$\left[\mathrm{VO}(\mathrm{IV})-(\mathrm{MNPH})_{2}\right]$} & 250 \\
\hline
\end{tabular}

\section{ACKNOWLEDGEMENT}

We thank the MAPCOST, Bhopal for Financial support, Government Motilal Vigyan Mahavidyalaya, Bhopal for providing Laboratory facilities and are also thankful to Dr. Hharshita Shah, People's College of Medical Science and Research Centre for providing Anti-tubercular activity.

\section{REFERENCES}

[1] M. C. Rodriguez-Aguelles, M.B.Ferrari,F. Bisceglie,C.Pelizzi, G. Pelosi, S. Pinelli, M. Sassi, J. Inoorganic Biochemistry, 98, 313. 2004

[2] K. Uehara, K. Morimoto, Y. Shijo, Analyst., 117, 977. 1992

[3] I. A. Tossadis, C. A. Bolos, P. n. Aslanidis, G. A. Katsoulos, Inorg. Chim. Acta, 133, 275. 1987.

[4] J. A. Anten, D. Nicholis, J. M. Markpouos, O. Markopoulou, Polyhedron, 6, 1074. 1987

[5] A. Maiti, S. Ghosh, Indian J. Chem., 28A, 980. 1989

[6] R. C. Aggarwal, N. K. Singh, R. P. Singh, Inorg. Chim. Acta, 29, 2794 1981.

[7] J. C. Craliz, J. C. Rub, D. Willis, J. Edger, Nature, 34, 176. 1955

[8] J. R. Dilworth, Coord. Chem. Rev., 21, 29. 1976.

[9] J. R. Merchant, D. S. Clothia, J. Med. Chem., 13, 335. 1970

[10] N. S. Biradar, B. R. Havinale, Inorg. Chim. Acta, 17, 157. 1976

[11] H. N. Fox, Science, 116, 129. 1952. 
[12] P. A. S. Smith, The Chemistry of open-chain organic nitrogen compounds, New York Vol. 2, 119. 1996

[13] R.B. Singh, K. P. Jain, R. P. Singh, Talanta., 29, 77. 1982

[14] M. E. U. Pozo, A. G. De Torres, J. M. C. Pavon, Analyst, 113, 547. 1988

[15] A. Asuero, A. M. Jimenez, M. A. Herrador, Analyst, 111, 747. 1986

[16] G. Nickless, J. Chromatogr., 313, 129. 1985

[17] Z. Liu, F. C. Anson, Inorg. Chem., 40, 1333. 2001

[18] D.Rehder, Coord. Chem. Rev., 182, 297. 1999

[19] K. H. Thomson, J. H. Mcneil, C. Orvig, Chem. Rev., 99, 2561. 1999

[20] M. R. Maurya, S. Khurana, Shailendra, A. Azam, W. Zhang, D. Rehder, Eur. J. Inorg. Chem., 1966. 2003

[21] A. M. Evangelon, CR Oncol/Hemat, , 42, 249. 2002

[22] R. K. Agarwal, I. Chakraborti, Polish J. Chem., 68, 1491. 1994

[23] The trans influence of the oxo ligand is reviewed by E. M. Shustrovitch, M. A. Porikoshits, Yu. A. Buslaev, Coord. Chem. Rev., 17, 1. 1975

[24] M. Sayaji Rao, K. Hussain Reddy, Indian J. Chem., 38A, 262. 1999

[25] G. Paolucci, G. Marangoni, G. Barnoli, D. D. Clemente, J. Chem. Soc. Dalton Trans, 1304. 1980

[26] V. Pradhan, Oriental Jour. of Chem., 10, No. 1, 87-89. 1994

[27] A. Pradhan, J. Indian Chem. Sic., 80, 143-144. 2003

[28] Clinical Diagnosis and Management by laboratory methods, Todd, Sanford and Davidson, 17 $^{\text {th }}$ edition, Edited by John Bernard Henry. 1998

[29] Practical medical Microbiology Mackie and Mc Cartney, $13^{\text {th }}$ edition, Edited by J. G. College, J. P. Dugoid. 1989

[30] Diagnostics Microbiology, Bailey and Scotts. 